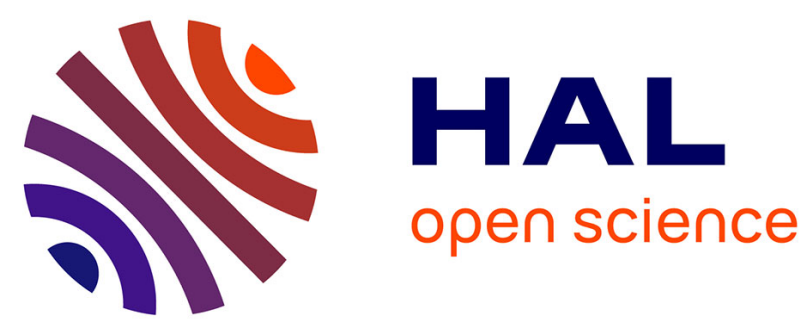

\title{
ANALYSIS OF LASING TRANSITIONS IN A LASER-PRODUCED SELENIUM PLASMA
}

\author{
S. Jacquemot, E. Berthier, M. Vuillemin, M. Cornille
}

\section{To cite this version:}

S. Jacquemot, E. Berthier, M. Vuillemin, M. Cornille. ANALYSIS OF LASING TRANSITIONS IN A LASER-PRODUCED SELENIUM PLASMA. Journal de Physique Colloques, 1986, 47 (C6), pp.C6-339-C6-344. 10.1051/jphyscol:1986642 . jpa-00225886

\section{HAL Id: jpa-00225886 https://hal.science/jpa-00225886}

Submitted on 1 Jan 1986

HAL is a multi-disciplinary open access archive for the deposit and dissemination of scientific research documents, whether they are published or not. The documents may come from teaching and research institutions in France or abroad, or from public or private research centers.
L'archive ouverte pluridisciplinaire HAL, est destinée au dépôt et à la diffusion de documents scientifiques de niveau recherche, publiés ou non, émanant des établissements d'enseignement et de recherche français ou étrangers, des laboratoires publics ou privés. 


\title{
ANALYSIS OF LASING TRANSITIONS IN A LASER-PRODUCED SELENIUM PLASMA
}

\author{
S. JACQUEMOT, E. BERTHIER, M. VUILLEMIN and M. CORNILLE* \\ Commissariat à 1 'Energie Atomique, Centre d'Etudes de \\ Limeil-Valenton, B.P. $n^{\circ}$ 27, F-94190 Villeneuve-Saint-Georges, \\ France \\ *Processus Atomiques et Moléculaires en Astrophysique (UA 812), \\ observatoire de Meudon, F-92195 Meudon, France
}

RESUME - Des calculs de forces de collision et de taux de desexcitation radiative ont été effectués pour 8 configurations $\left(1 \mathrm{~s}^{2} 2 \mathrm{~s}^{2} 2 \mathrm{p}^{6}, 2 \mathrm{p}^{5} 31\right.$ et $41^{\prime}$, si $1=0,1,2$ et $1^{\prime}=0,1,2,3$ ) du selenium neonoïde (Se XXV). A partir de ces données atomiques ont étê calculées les différentes populations des niveaux décrivant un plasma de selenium produit par laser en fonction de l'évolution hydrodynamique de celui-ci.

L'analyse de ces populations a permis de mettre en évidence l'existence d'inversions et de transitions "lasantes", en particulier entre les configurations $2 p^{5} 3 p-3 s, 4 p-3 d$ et $4 f-3 d$.

$\triangle B$ BSRACT - We present calculations of electron impact collision strengths and spontaneous radiative decay rates for 8 neon-like selenium ( Se XXV) configurations $\left(1 \mathrm{~s}^{2} 2 \mathrm{~s}^{2} 2 \mathrm{p}^{6}, 2 \mathrm{p}^{5} 31\right.$ and $41^{\prime}, \quad 1=0,1,2$ and $\left.\mathrm{I}^{\prime}=0,1,2,3\right)$.

From these atomic data the level populations are calculated in a laser produced selenium plasma as a function of its time-evolving hydrodynamical profile (electron temperature and density).

The analysis of these populations involves the existence of lasing transitions, especially between the $2 \mathrm{p}^{5} 3 \mathrm{p}$ and 3 s configurations, but also between the $4 \mathrm{p}$ and $3 \mathrm{~d}$, or $4 \mathrm{f}$ and $3 \mathrm{~d}$ one.

Hydrodynamical plasma conditions

According to the L.L.N.L, X-ray laser experiments /1/, we decide to study a thin se foil (750A deposited on $1500 \mathrm{~A}$ of solid $\mathrm{CH}_{2}$ : Fig.l). This target was irradiated by a single beam of a $0.53 \mu \mathrm{m}$ laser 1 ight, with a $510^{13} \mathrm{~W} / \mathrm{cm}^{2}$, 315ps flat-topped illumination (Fig.2). 


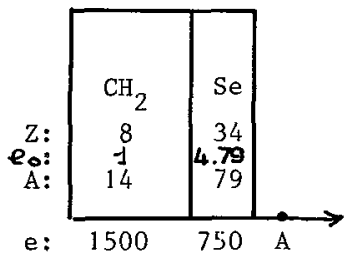

Fig.1. Se target design
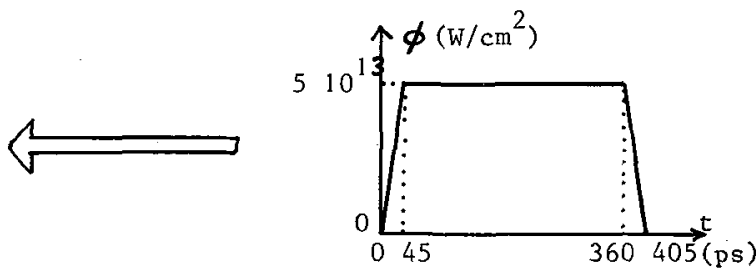

Fig.2. Laser illumination

The hydrodynamical 1-D code CHIVAS/2/, coupled with the ionization model CORINNE $/ 3 /$, allows us to describe the temporal plasma evolution (Fig.3) The 1 aser energy is supposed absorbed by inverse Bremsstrahlung and by a local deposition of $10 \%$ at the laser cut-off density. A heat-flux limiter equal to 0.05 is taken into account.

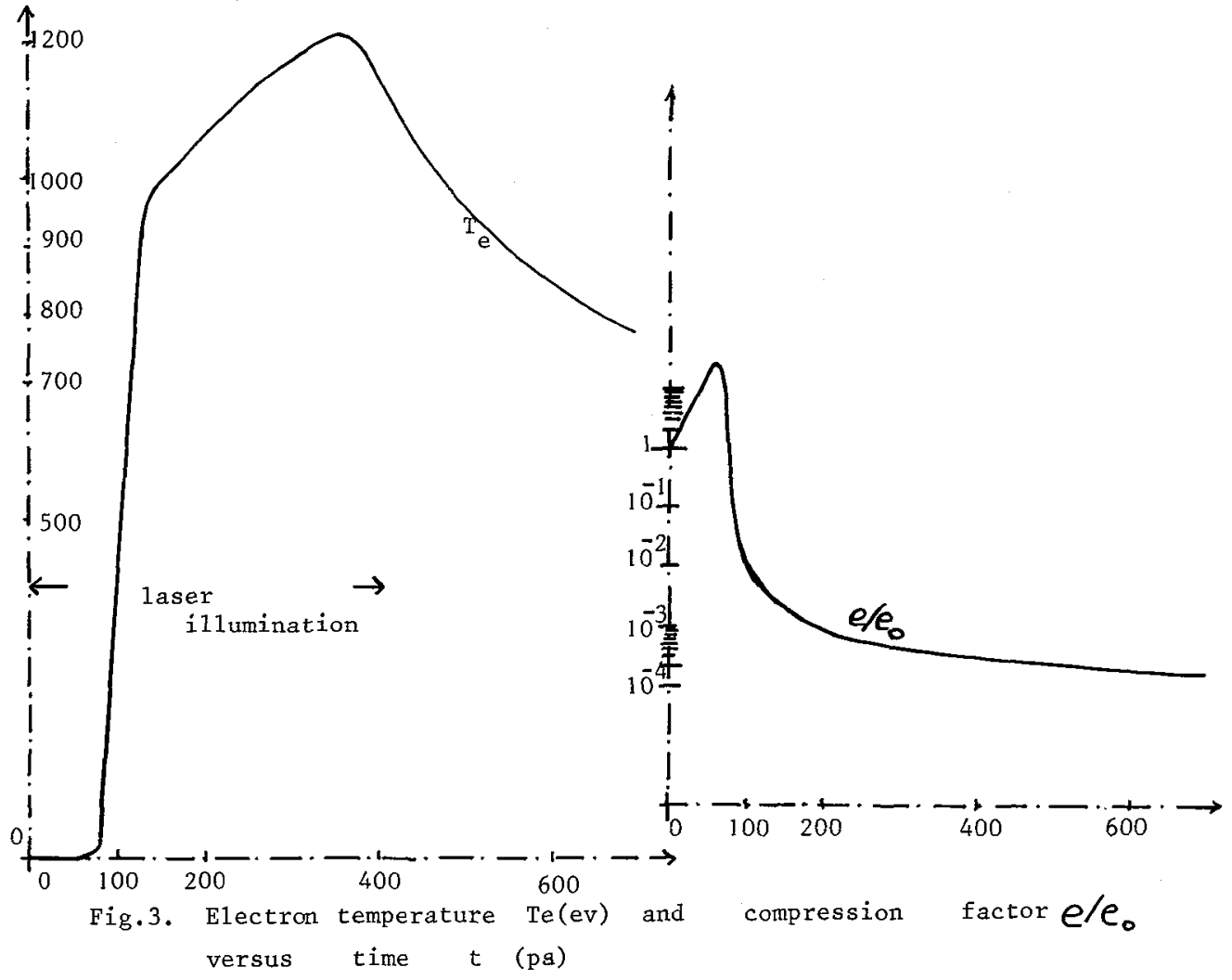

\section{Atomic structure calculations}

An atomic model of highly ionized selonium has been constructed. It includes the six most relevant configurations of Se XXV : the ground state $1 s^{2} 2 s^{2} 2 p^{6}$ and the $n=3-n=4$ configurations $1 s^{2} 2 s^{2} 2 p^{5} 31$ and $41^{\prime}$ (for $1=0$, 1,2 and $\left.1^{\prime}=0,1,2,3\right)$, which represent 65 leve1s in LSJ coupling. The excited 
levels above $4 \mathrm{f}$ through $\mathrm{n}=9$ are consolidated by principal quantum numbers. This plasma model is completed by the ground states of the other ionization stages, consolidated by seven n-leve1s.

The 328 various states are coupled by electron collisional excitation and de-excitation, spontaneous radiative decay, collisional ionization and threebody, radiative or dielectronic recombination.

The main atomic problem becomes the determination of configuration interaction wawefunctions and energies from which can be deduced the different needed parameters. The energy levels, statistical weights and spontaneous radiative probabilities are calculated in LSJ coupling by the SUPERSTRUCTURE computer code $/ 4 /$ which derives from a relativistic modified Thomas-Fermi statistical potential approximation and assumes wavefunctions as linear combinations of Siater determinants, developed on a basis of the four monoelectronic orbitals s, p, d and $f$. The scaling parameters of the potential are obtained by a minimization procedure based upon some selected neonlike configurations : $1 s^{2} 2 s^{2} 2 p^{6}$ and $2 p^{5} 31 \quad(1=0,1,2)$.

$$
\begin{aligned}
& \lambda_{s}=1.1727 \\
& \lambda_{p}=1.0873 \\
& \lambda_{d}=\lambda_{f}=1.0963
\end{aligned}
$$

The scattering problem was carried out in a distorted wave approximation using the computer package SUPERSTRUCTURE + DW + JJOM $/ 5 /$, an electron-collision cross-section program which calculates collision strengths, in fine-structure coupling, versus incident electron energy (here, 160 Rydbergs). The contribution to these strengths from high partial waves $(1>20)$ is taken into account in a Coulomb-Bethe approximation. The main collision strengths at 160 . Rydbergs $(\Omega)$, radiative probabilities $\left(A\right.$, in $s^{-1}$ ) and wavelengths $(A$ in $\AA$ ) are represented on Fig.4.

A11 the hydrodynamical and atomic data that we calculate in the first part of this analysis are then introduced in the LIMEIL computer code LASIX $/ 6 /$.

This program first determines the temporal evolution of the plasma : the average charge $\bar{Z}$, the rates $r(z)$ of the different existent ions (where $z$ is the nuclear charge of the studied ion), and the electron density $n_{e}$ (Fig.5).

After the end of the laser illumination, the average nuclear charge $\bar{z}$ may be considered as constant :

$$
\bar{z}=25.70
$$

and four ionization degrees prevail in the plasma :

$$
z=28(N)-z=27(0)-z=26(F)-z=25(\mathrm{Ne})
$$

with a predominance of the oxygenlike and fluorinelike ions, which explains the importance that the different recombination processes take in the determination of 


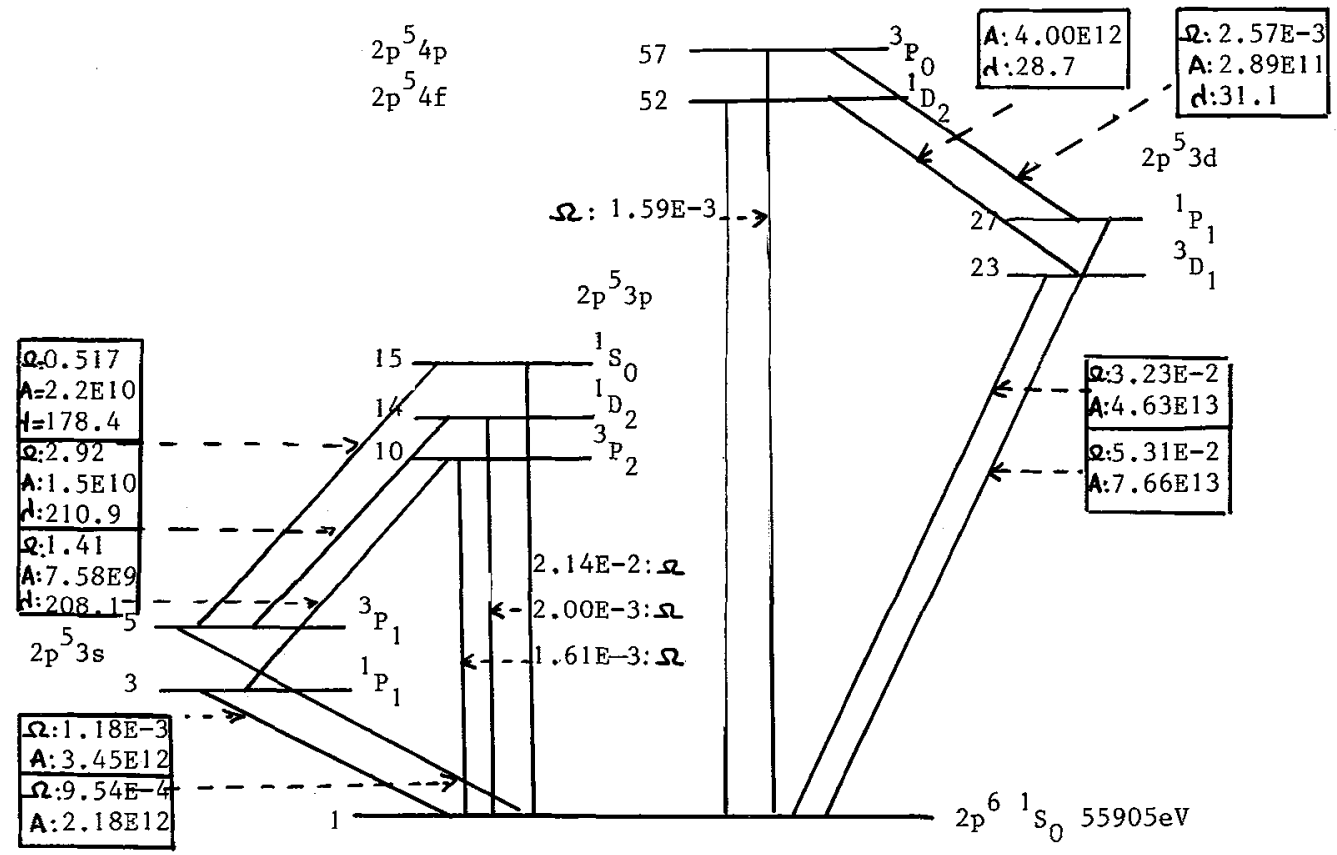

Fig. 4 . Lasing scheme and main atomic data

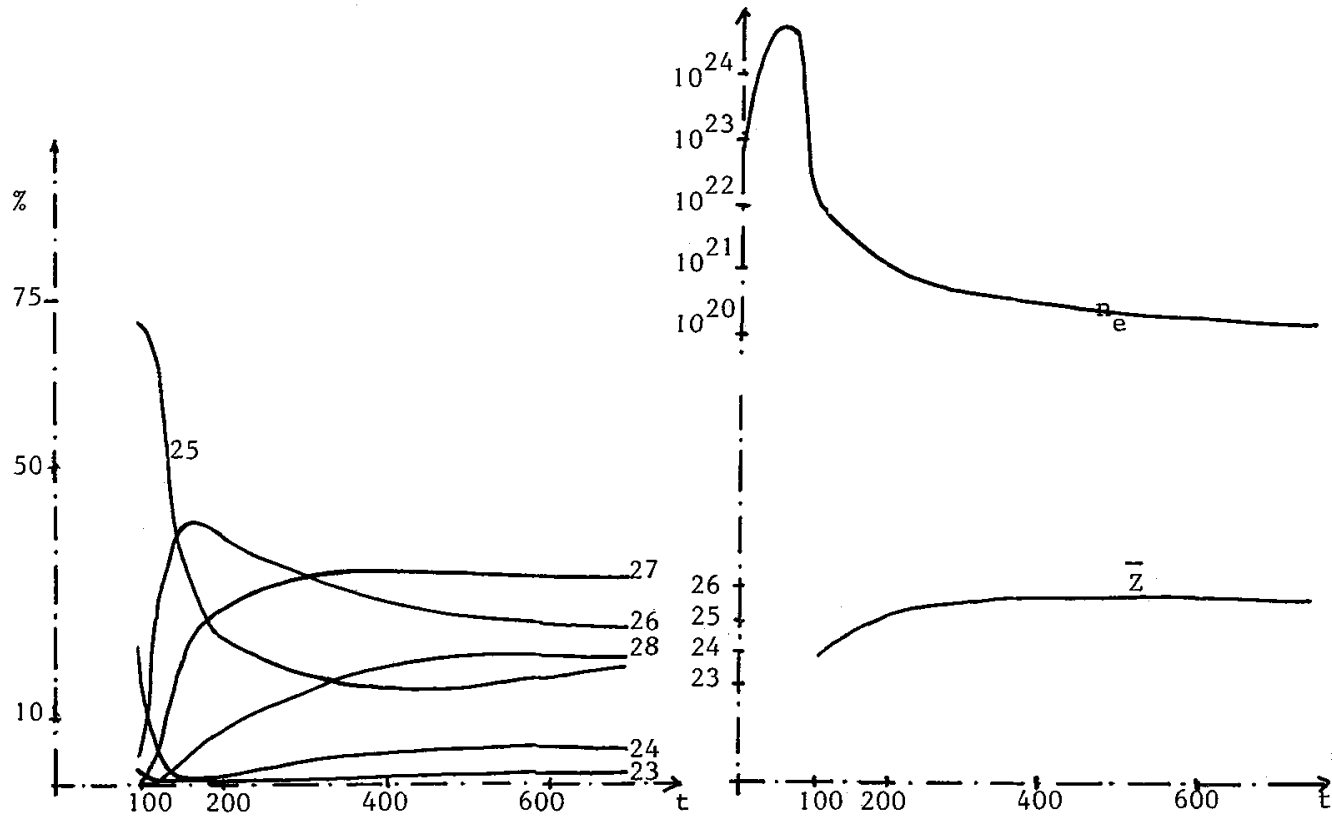

Fig. 5 . Temporal evolution of the different nucleas charges in the selenium plasma and of the electron density $n_{e}\left(\mathrm{~cm}^{-3}\right)$ versus time $t$ (ps). 
the ionization balance and of the detailed level populations.

Then, LASIX solves the set of coupled equations :

$$
\begin{aligned}
\frac{d P_{i}=}{d t}= & -P_{i}\left(\sum_{j<i}\left(A_{i j}+n_{e} c_{i j}^{d}\right)+n_{e} \sum_{j>i} c_{i j}^{e}+x\right) \\
& +\sum_{j>i} P_{j}\left(A_{j i}+n_{e} c_{j i}^{d}\right)+n_{e} \sum_{j<i} c_{j i}^{e}+Y
\end{aligned}
$$

where $\mathrm{X}$ and $\mathrm{Y}$ represent the contribution of the ionization-recombination processes in the population and depopulation of the $i^{\text {th }}$ level $\left(P_{i}\right) \cdot C_{i j}$ is the collisional excitation (e) (or de-excitation (d)) rate coefficient.

The formulation of these rate coefficients is classical :

$\mathrm{C}_{\mathbf{i j}}$ is a function of the collisional strength $\Omega_{\mathrm{ji}}$ :

$$
\mathrm{C}_{i j}^{\mathrm{d}}=8.01510^{-8} \Omega_{j i} / \mathrm{g}_{i} \mathrm{~T}_{\mathrm{e}}^{-1 / 2} \quad\left(\mathrm{~cm}^{3} \mathrm{~s}^{-1} ; \mathrm{eV}\right)
$$

$g_{i}$ being the statistical weigth of the $i^{\text {th }}$ level, while collisional ionization and radiative recombination rate coefficients derive from semi-empirical formulae ( Lotz /7/ and Seaton /8/). The dielectronic recombination rate coefficient has been previously determined $(/ 9 /)$.

The calculated populations can be represented per unit statistical weigth to show the existence of the classical inversions $3 p-3 s$ but also of $4-3$ one ( Fig. 6). The gain coefficient for these lasing transitions is supposed to be given, if Doppler broadening is the main source of line broadening, by. :

$$
\alpha=1.43710^{-7} \mathrm{~T}_{e}^{-1 / 2} \lambda_{i j}^{3} A_{i j} g_{i}\left(\frac{P_{i}}{g_{i}}-\frac{P_{j}}{g_{j}}\right) \quad\left(\mathrm{cm}^{-1}\right. \text {, Fig. 7) }
$$

Analysis and conclusion

The short-wavelength transitions (with change of principal quantum number) present, in such described hydrodynamical plasma conditions, gains never exceeding $0.1 \mathrm{~cm}^{-1}$ and therefore are not interesting as $\mathrm{x}$-ray laser possibilities. In fact, the main result of this study is the restitution of the Livermore $x$-ray experiments' conclusions : as far as the $3 p-3$ s transitions in neonlike selenium are concerned, the highest gains must be expected for the $\mathrm{J}=2$ to $\mathrm{J}=1$ 1ines (at $206 \AA$ and $210 \AA$ ) while the $J=0$ to $J=1$ transition( at $183 \AA$ ) presents a lower gain $\left(0.25 \mathrm{~cm}^{-1}\right)$.

In summary, it seems that, to calculate correct gains in laserproduced plasmas, it should be necessary to do accurate evaluations of dielectronic recombination rate coefficients and collision strengths and to use time-dependent mode1s. 


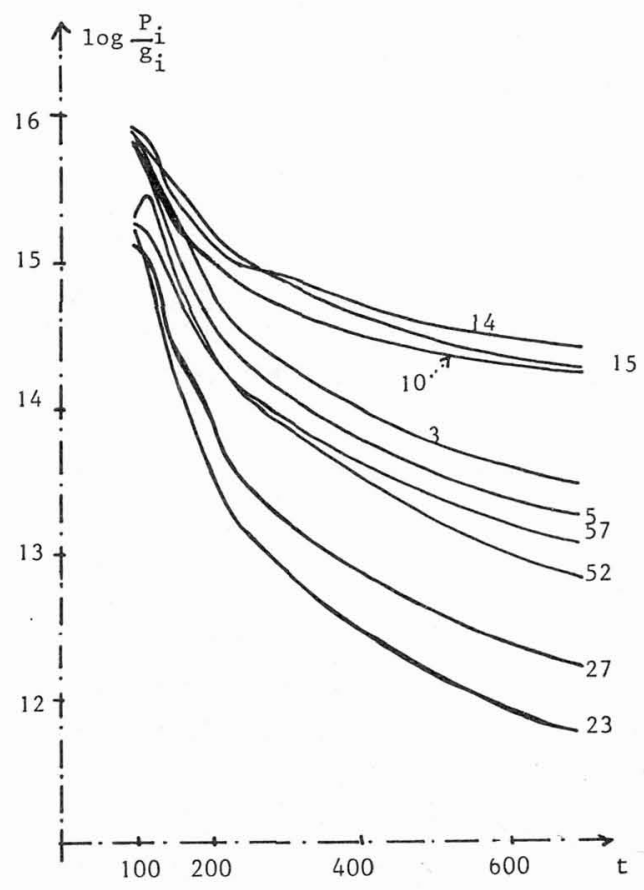

Fig. 6 . Relative level populations per unit statistical weigth $\left(\mathrm{cm}^{-3}\right)$ versus time (ps)

(numbers $5,3,10,14,15,23,27,52$

and 57 refer to Fig.4)

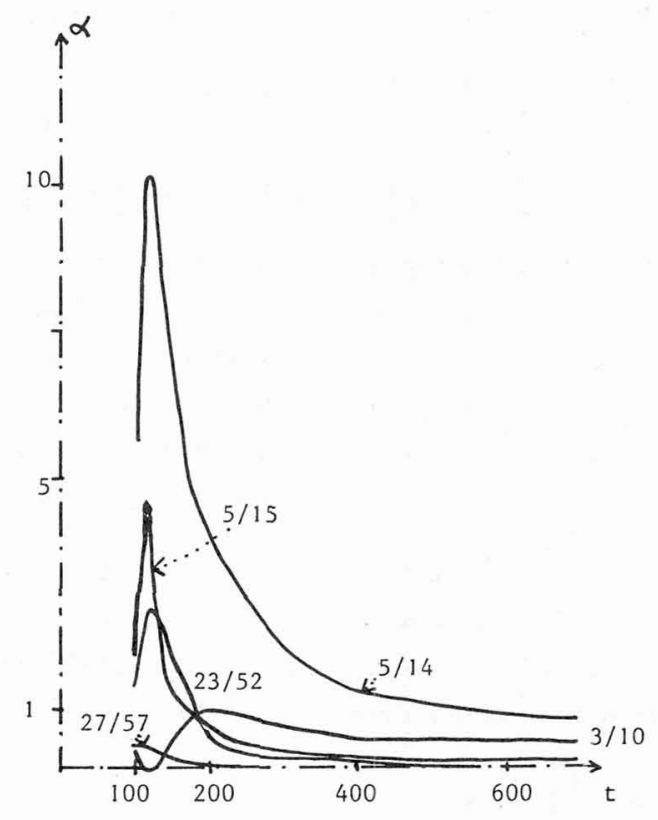

Fig. 7 . Gain coefficients $\left(\mathrm{cm}^{-1}\right)$ versus time (ps)

\section{References}

1. M.D. Rosen and al., Phys. Rev. Lett. 54, 106 (1985)

2. P. Aussage, J. Faure, C.E.A. Limeil

3. G. di Bona,D. Babonneau and a1. ,XIII th. Int, Quantum Elec. Conf. TUCC5 (1984)

4. W. Eissner,M. Jones, H. Nussbaumer, Comp. Phys. Comm. 8,270 (1974)

5. H.E. Saraph, Comp. Phys. Comm. 3,256 (1972)

6. E. Berthier,J.F. De1pech,M. Vuillemin:preceding letter

7. W. Lotz, Z. für Physik 220,466 (1969)

8. M.J. Seaton, M.N.R.A.S. $119,2,81$ (1959)

9. M. Cornille,J. Dubau,S. Jacquemot:following letter 